\title{
Thermal distribution and response in Q-switched ruby laser treatment for oculodermal melanosis (Nevus of Ota)
}

\author{
David Cheong Chon Fok ${ }^{1}$, Cheng-Jen Chang ${ }^{1,2}$, Yun-Liang Suㄹ, Shu-Ying Chang', Yen-Chang Hsiao', Kuen Ting ${ }^{4}$, \\ Wen-Shiung Lin ${ }^{4}$, Kuen-Tasnn Chen ${ }^{3}$, Shih-Feng Chen ${ }^{4}$
}

${ }^{1}$ Department of Plastic Surgery, Chang Gung Memorial Hospital, Chang Gung University, Taoyuan 333, Taipei, China.

${ }^{2}$ Department of Plastic Surgery, Taipei Medical University Hospital, Taipei 110, Taipei, China.

${ }^{3}$ Department of Applied Mathematics, National Chung Hsing University, Taichung 402, Taipei, China.

${ }^{4}$ Department of Mechanical Engineering, Lunghwa University of Science and Technology, Taoyuan 333, Taipei, China.

Correspondence to: Prof. Cheng-Jen Chang, Department of Plastic Surgery, Taipei Medical University Hospital, Taipei 110, Taipei, China. E-mail: chengjen@h.tmu.edu.tw

How to cite this article: Fok DCC, Chang CJ, Su YL, Chang SY, Hsiao YC, Ting K, Lin WS, Chen KT, Chen SF. Thermal distribution and response in Q-switched ruby laser treatment for oculodermal melanosis (Nevus of Ota). Plast Aesthet Res 2017;4:1-8.

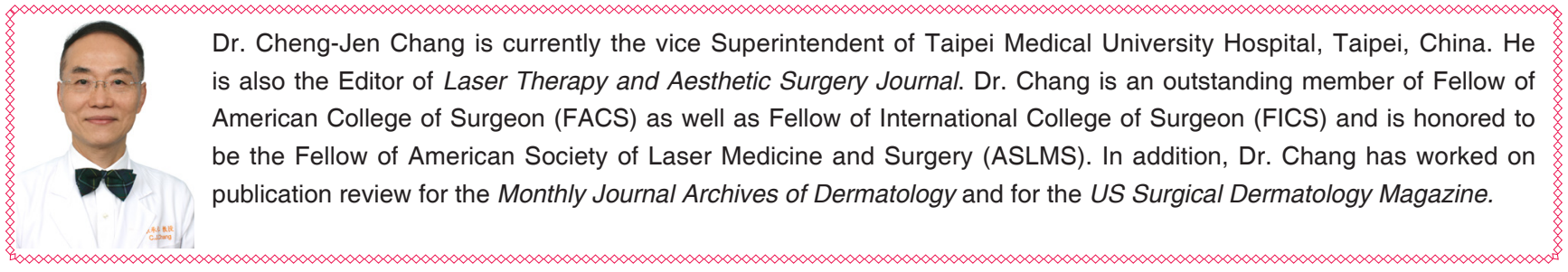

Article history:

Received: 11-10-2016

Accepted: 13-10-2016

Published: 19-01-2017

Key words:

Infrared thermal imaging,

thermal wave equation,

Q-switched ruby laser,

Nevus of Ota

\begin{abstract}
Aim: A clinically useful treatment laser must generate stable and precise energy of low diffusivity. This study assessed the photothermal response of a Q-switched ruby laser (QSRL) in the treatment of oculodermal melanosis (Nevus of Ota). Methods: A two-year retrospective review of 40 patients with oculodermal melanosis treated with a QSRL $(\lambda=694 \mathrm{~nm}$, pulse duration $=25 \mathrm{~ns}, 3 \mathrm{~mm}$ spot size, energy density $6-10 \mathrm{~J} / \mathrm{cm}^{2}$ ) was performed. Demographics included an age range of 18-54 years (mean 28) and a gender distribution of 25 females and 15 males. The values recorded from real-time infrared thermal imaging of the lasered skin were inserted into standard thermal wave equations. This permitted analysis of the resultant temperature distributions related to the energy change. Results: Skin temperature was unchanged during the initial heating stage. This was followed by a very rapid temperature rise. A thermal burn injury manifested by dermal-epidermal disruption, resulted when the energy density of the QSRL exceeded $8 \mathrm{~J} / \mathrm{cm}^{2}\left(>44{ }^{\circ} \mathrm{C}\right)$. Conclusion: The use of infrared thermal imaging with a standard thermal wave equation allows prediction of skin temperature distribution when QSRL is used for the treatment of oculodermal melanosis. With the use of appropriate settings, complications may be minimized.
\end{abstract}




\section{INTRODUCTION}

Treatment lasers generate a high influx of energy over a short period of time. As such, the energy generated must be of high stability and precision..$^{[1-3]}$ Laser techniques have been successfully and broadly used in skin surgery. However, the various chromophores within the skin react differently, according to the absorption and scattering of the individual wavelengths of the lasers used. As such, lasers of different wavelengths can be used to treat various pathological skin conditions.

A nevus fusco-caeruleus ophthalmomaxillaris (oculodermal melanosis or Nevus of Ota) is a syndrome consisting of blue-black or gray-brown patchy pigmentation. It may be either unilateral or bilateral, and most commonly occurs in the trigeminal nerve dermatome. The lesions are present at birth in approximately $60 \%$ of cases and occur most commonly in patients that are of Asian descent or dark-skinned individuals. ${ }^{[1]}$ Histologically, the melanin pigment is seen contained within the dendritic dermal melanocytes, similar to that in Mongolian spots. Macular blue staining of the sclera on the affected side is seen frequently. When this occurs, melanocytic infiltration of the corneal, conjunctive, and intraocular structures may be observed. ${ }^{[2-5]}$ The effects of oculodermal melanosis transcend cosmesis as it may be associated with potentially devastating psychological complications. Personality development may be affected due to the adverse societal and cultural reactions to a "marked person".

Numerous treatment modalities have been described for oculodermal melanosis. ${ }^{[6-9]}$ The laser systems include the Argon (488 $\mathrm{nm}$ and $514 \mathrm{~nm}$ ) and Q-switched ruby lasers (QSRL) (694 $\mathrm{nm}$ ) [Figures 1 and 2]. ${ }^{[4,5,10-14]}$ The Q-switched alexandrite laser (QSAlexL) (755 nm) and the Q-switched Neodymium:Yttrium-AluminumGarnet laser (QS Nd:YAGL) (1,064 nm) have taken preference for clinical treatment of benign epidermal pigmented lesions of the skin, such as oculodermal melanosis. ${ }^{[15,16]}$ However, if improper energy density is used, complications such as hypertrophic scarring and skin dyspigmentation may arise. ${ }^{[12,13,17-21]}$

Selective photothermolysis is effective when the target tissue chromophore matches the wavelength of the laser used, with minimal collateral damage. ${ }^{[22]}$ Because the laser energy is packed into a very short delivery time period, the target tissues exhibit photothermal phenomena by absorbing the high energy of a laser beam nearly instantaneously, where surrounding tissue is narrowly affected. Therefore, the energy is capable of damaging target tissues and not injuring

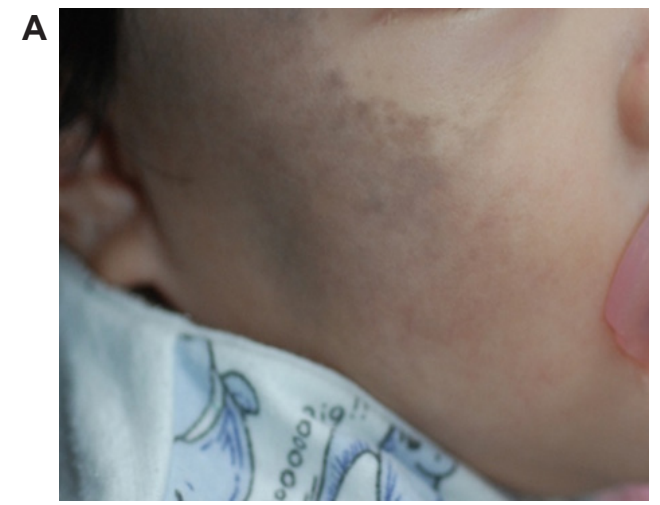

B

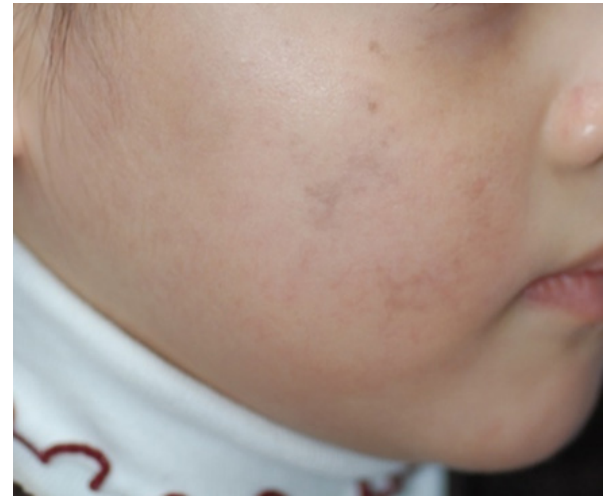

Figure 1: A 4-year-old Asian girl with Nevus of Ota of the right cheek: (A) prior to laser therapy; and (B) 2 years after two treatments with $Q$-switched ruby laser $(694 \mathrm{~nm})$ using an energy density of $8-9 \mathrm{~J} / \mathrm{cm}^{2}$. Result was evaluated as an excellent cleaning and fading response
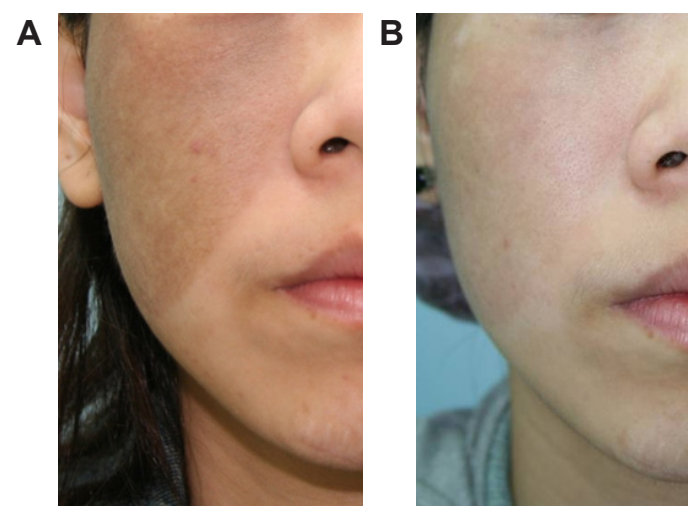

Figure 2: A 19-year-old Asian female with Nevus of Ota of the right cheek: (A) prior to laser therapy; and (B) 2 years after four treatments with Q-switched ruby laser (694 $\mathrm{nm}$ ) using an energy density of $9-10 \mathrm{~J} / \mathrm{cm}^{2}$. Result was evaluated as an excellent cleaning and fading response

the surrounding skin -- a concept closely related to the knowledge of heat transfer. On the other hand, the photothermal phenomenon is due to the explosion of the pigment chromophore. This is because the energy that the pigment has absorbed has no time to dissipate and thus ruptures. It is the dissipation of heat energy that causes surrounding tissue damage. Such an understanding of the temperature distribution on the skin surface will contribute to effective laser surgery 
and will result in the prediction of skin temperature distribution and the study of skin burn injury -- important issues in laser treatment. ${ }^{[23]}$ However, more information on the thermal response and temperature distribution during laser treatment is needed to avoid permanent complications.

Differential scanning calorimeters have been used to evaluate the surface heat flux, temperature, and heat absorption rate at the skin surface. An infrared thermal imaging device was used in this study to measure skin temperature in laser skin surgery. The main objectives of this study focus on the analysis and evaluation of skin temperature during laser application. This will in turn, assist medical practitioners in assessing and treating the reaction of skin to laser energy and avoiding complications. ${ }^{[24]} \mathrm{A}$ heat transfer analysis using the thermal wave equation helps us to learn the importance of the thermal wave theory of photothermal effects. Using an infrared thermal image instrument and with the thermal changes obtained using a thermal wave equation, the reliability of the analytic solution will be ensured. Further discussion of the QSRL used in cutaneous laser surgery is presented to provide knowledge of the temperature changes of patients' skin during laser treatment. With this, more accurate predictions of skin surface temperature can be achieved which could serve as treatment references for researchers and clinicians.

\section{METHODS}

From January 2010 to June 2012, 40 patients with oculodermal melanosis treated with the $694 \mathrm{~nm}$ QSRL (Derma-Laser, Hopkinton, MA, USA) at the settings of $25 \mathrm{~ns}$ pulse duration, energy densities of $6-10 \mathrm{~J} / \mathrm{cm}^{2}$, with a spot size of $3 \mathrm{~mm}$ were observed in this retrospective study. The age range was 18 to 54 years, with a mean of 28 years. There were 25 females and 15 males. Based on pretreatment photographs, each oculodermal melanosis was assigned a severity grade using the Tanino classification system. ${ }^{[25]}$ Patients were grouped into four different clinical types: (1) mild; (2) moderate; (3) intensive; and (4) bilateral. Observation was analyzed based on the following variables: age, gender, severity, number of treatment(s), duration of treatment(s), and improvement following laser therapy. The study protocol was approved by the Institutional Review Board at Chang Gung Memorial Hospital. Inclusion criteria for the study was: (1) oculodermal melanosis suitable for comparison testing; (2) oculodermal melanosis greater than $20 \mathrm{~cm}^{2}$; and (3) apparent good health as documented by medical history. The following exclusion criteria was determined as: (1) inability to commit to a three month follow-up period; (2) pregnancy; (3) history of photodermatoses or skin cancer; (4) concurrent use of known photosensitizing drugs; and (5) any therapy within the previous 2 months to the proposed oculodermal melanosis test sites.

For the infrared thermal imaging study, 5 QSRL test sites were prospectively identified on each patient for treatment assignment according to the following parameters: $6,7,8,9$, and $10 \mathrm{~J} / \mathrm{cm}^{2}$. Laser energy was delivered to the skin through an optical fiber and lens that focused the beam onto a $3 \mathrm{~mm}$ spot on the lesion. The untreated area was assigned as a control. Sites were assigned to one-treatment regimens by randomization. Every effort was made to place the test sites on optically uniform areas of the lesion to ensure that clinically relevant oculodermal melanosis characteristics and geometry (i.e. epidermal melanin concentration and depth) did not substantially vary between each of the test sites on an individual patient basis. Photographs were taken of the test sites after treatment regimen assignment and at follow-up visits.

The imaging and changes of skin temperature were measured in real time using an infrared thermal image instrument (ThermaCAM ${ }^{\mathrm{TM}}$ S60, FLIR System, Danderyd, Sweden). The results of temperature distributions related to the energy variance were analyzed. Data of the skin surface temperatures measured by the infrared thermal image instrument was put into the analytic solutions of the thermal wave equation with comparisons made between the results. ${ }^{[26]}$ The clearing and fading result of pigmentation was assessed by a DermoSpectrometer (Cortex Tech., Hadsund, Denmark) to calculate the melanin-index at follow-up visits for each of the test site treatment regimens. ${ }^{[27-29]}$

The device emits light from diode sources at two defined wavelengths. The amount of light backscattered from the skin is then used to determine the indices for hemoglobin/melanin. Therefore, care was taken to make each measure with the device in contact with the skin, but without the application of pressure to the test site. The melanin index for pre-treated lesions, along with those of treated oculodermal melanosis, was also measured. The patients were observed after treatment(s), and those calculations were used to display a better correlation with how the oculodermal melanosis differed from the initial pre-treated lesion calculations. Differences between the responses of each site before and after QSRL treatment were then determined and analyzed. Patients were also closely monitored for any adverse effects. Each of the test sites was examined for unfavourable wound characteristics such as blistering, scabbing, erosion and scarring. The primary measure of efficacy was 
Table 1: Skin surface temperatures for Q-switched ruby laser treatment for different energy density

\begin{tabular}{lcc}
\hline \multirow{2}{*}{ Energy density $\left(\mathbf{J} / \mathbf{c m}^{2}\right)$} & \multicolumn{2}{c}{ Skin surface temperature $\left({ }^{\circ} \mathrm{C}\right)^{\dagger}$} \\
\cline { 2 - 3 } & $\mathbf{I R}^{\star}$ & Thermal wave equation \\
\hline 6 & $40.8 \pm 0.3$ & $41.2 \pm 0.2$ \\
7 & $41.9 \pm 0.3$ & $42.5 \pm 0.4$ \\
8 & $44.1 \pm 0.4$ & $44.3 \pm 0.3$ \\
9 & $46.9 \pm 0.2$ & $47.6 \pm 0.2$ \\
10 & $50.8 \pm 0.4$ & $51.5 \pm 0.4$ \\
\hline
\end{tabular}

${ }^{\dagger}$ : baseline skin surface temperature $-32.4 \pm 0.2{ }^{\circ} \mathrm{C} ; \mathrm{IR}^{*}$ : temperatures measured by infrared thermal image instrument. $P=2 \times 10^{-11}$

Table 2: Mean melanin index of clearing and fading response of Nevus of Ota after Q-switched ruby laser treatment for different energy density

\begin{tabular}{lccc}
\hline Energy density $\left(\mathbf{J} / \mathbf{c m}^{2}\right)$ & 1 month & 3 months & $\mathbf{6}$ months \\
\hline 6 & $61.81 \pm 1.42$ & $55.77 \pm 1.76$ & $54.57 \pm 1.75$ \\
7 & $55.13 \pm 1.57$ & $54.82 \pm 1.63$ & $53.68 \pm 1.47$ \\
8 & $52.23 \pm 1.08$ & $47.85 \pm 1.39$ & $44.76 \pm 1.11$ \\
9 & $51.46 \pm 1.28$ & $46.69 \pm 1.07$ & $40.47 \pm 1.46$ \\
10 & $49.62 \pm 1.54$ & $45.78 \pm 1.74$ & $40.19 \pm 1.53$ \\
\hline
\end{tabular}

Mean-index of normal skin $=32.21 \pm 2.75$; mean-index of Nevus of Ota before $\mathrm{Q}$-switched ruby laser treatment $=63.15 \pm 1.44$

quantitative assessment. Differences between the temperatures measured and clearing/depigmentation response indices for each test site were determined.

\section{RESULTS}

A one-dimensional equation was used with fixed surface illumination time and variable laser energy densities of $6,7,8,9$, and $10 \mathrm{~J} / \mathrm{cm}^{2}$. The initial body temperature was set at $37{ }^{\circ} \mathrm{C} \cdot{ }^{[30]}$ An infrared thermal image instrument was used to measure the changes in surface skin temperature during QSRL treatment at the different energy densities. This showed the relationship between the energy densities and temperature changes of the QSRL illumination of the skin surface [Table 1]. Temperatures in the treated areas were observed to have risen significantly in response to laser exposure when the energy density of QSRL was higher than $8 \mathrm{~J} / \mathrm{cm}^{2}$ and thermal burn injury resulted (the temperature was higher than $44{ }^{\circ} \mathrm{C}$ ). In other words, the energy density should be less than $8 \mathrm{~J} / \mathrm{cm}^{2}$ if the QSRL is to treat skin pathological changes. Using the Irving-Fisher statistical test, there were statistically significant differences $(P$ $=2 \times 10^{-11}$ ). These results indicate that the severity of the involved area was not directly related to the final outcome but to the energy density of treatments. Some patients needed more number of treatment to prevent complications and sustain excellent results.

An infrared thermal image instrument was used to measure the changes in superficial skin temperature during QSRL treatment. The baseline skin surface temperature was $32.4 \pm 0.2{ }^{\circ} \mathrm{C}$. Over the time span

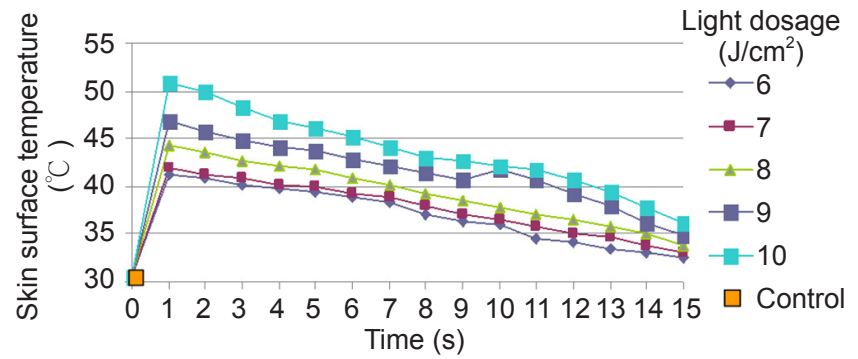

Figure 3: Temperature determination of superficial skin with infrared thermal image instrument for the Q-switched ruby laser treatment of the Nevus of Ota patients in different energy density

of $15 \mathrm{~s}$, the changes in temperature were recorded to assume proper care following treatment [Figure 3]. Based on what was observed in superficial skin regions, temperatures in those treated areas rose sharply within $5 \mathrm{~s}$ when there was a "T-jump" in response to laser exposure, and then immediately began to taper out and decrease gradually afterwards. The thermal wave equation showed that the baseline skin surface temperature $\left(32.4 \pm 0.2^{\circ} \mathrm{C}\right)$ and the tissue temperature inside the body $\left(37^{\circ} \mathrm{C}\right)$ were undisturbed at the initial stage of heating and then took an instantaneous jump, which can be viewed as a wave front resulting from a step change in temperature at the skin surface [Table 1]. ${ }^{[31]}$

The infrared images and temperature plots of normal skin and oculodermal melanosis-affected skin represent a patient's reaction time post-treatment, with a QSRL energy density of $9 \mathrm{~J} / \mathrm{cm}^{2}$ and the resulting temperature [Figures 4 and 5]. Other images and graphs were also taken of patients to display the different reaction times of superficial skin after laser treatment, in which temperature averages are clear over the course of 10, 20, and $30 \mathrm{~s}$. Injury due to laser illumination can be minimized while using optimum dosage to treat Nevus of Ota. A dermospectrometer was used to quantify the improvement in pigmentation at each of the follow-up visits at the following intervals of $1,3,6$, and 12 months [Table 2]. Although thermal burns did occur when the energy density of QSRL was higher than $8 \mathrm{~J} / \mathrm{cm}^{2}$, permanent scarring was not observed on any of the treated sites. Hyperpigmentation was noted in $5 \%(n=2)$ and delayed hypopigmentation was observed in $2.5 \%(n=1)$ of patients but was transient and resolved spontaneously without medical intervention in all patients.

\section{DISCUSSION}

Cutaneous laser surgery can be modeled on the short-term heat transfer behavior of iological tissues, particularly in hyperpigmented lesions such as oculodermal melanosis. When the surface of biological tissues is heated causing a temperature change, a series of complex changes in its biophysics and 

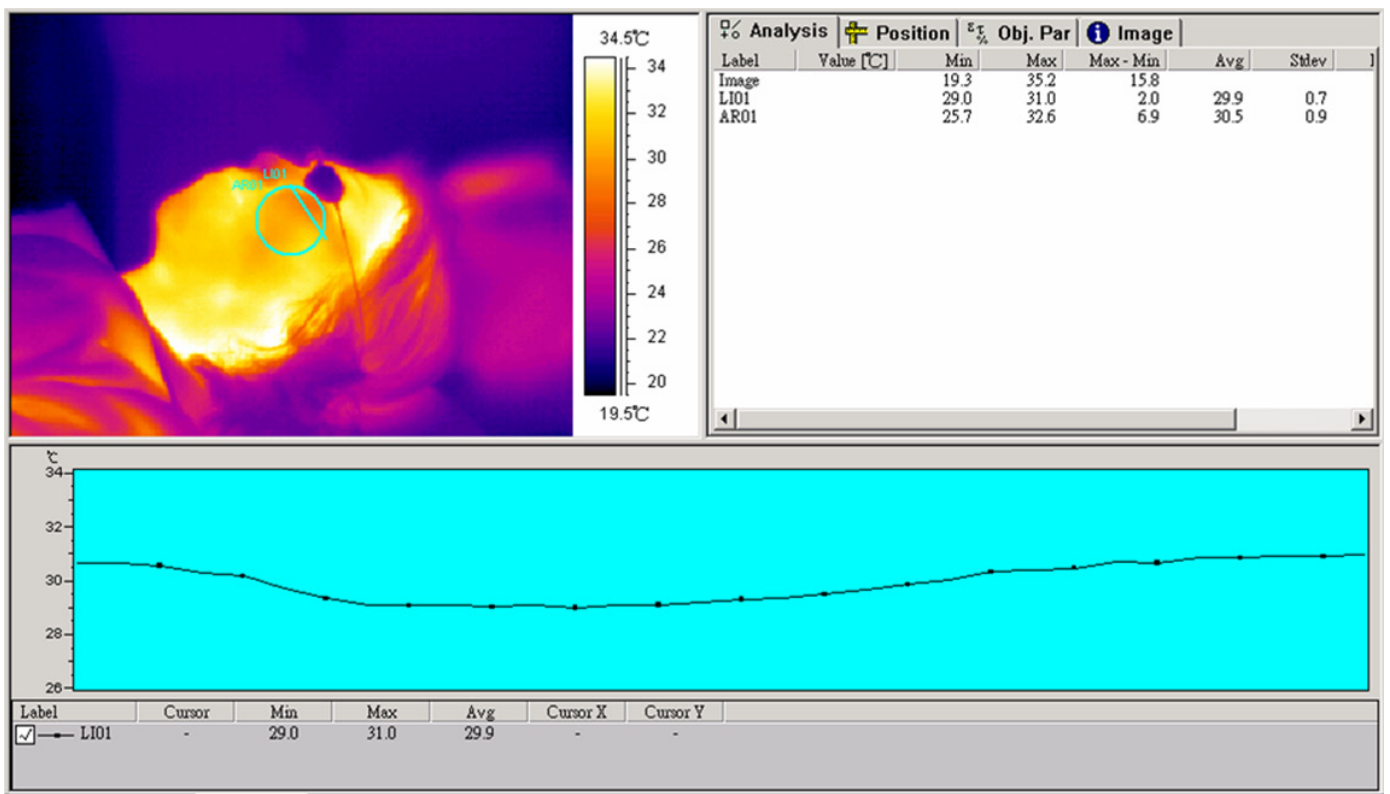

Figure 4: Plot of a patient's facial skin temperature before Q-switched ruby laser treatment for Nevus of Ota with infrared thermal image instrument
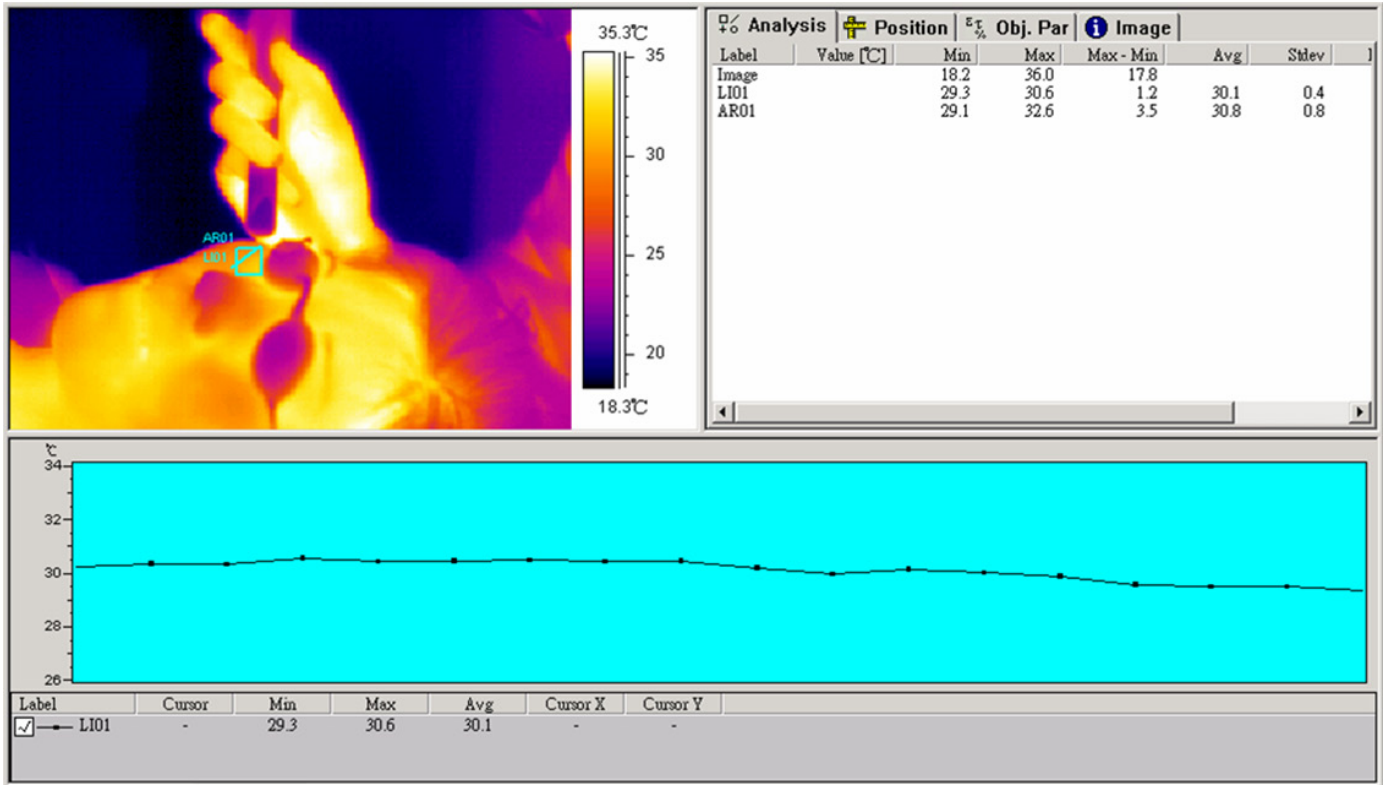

Figure 5: Plot of a patient's facial skin temperature $15 \mathrm{~s}$ after Q-switched ruby laser treatment with an energy density of $9 \mathrm{~J} / \mathrm{cm}^{2}$

biochemistry occurs ${ }^{\left[{ }^{[0]}\right.}$ As such, an perfect heat transfer analysis model is impossible obtain. It is common to use the Pennes equation to approximate the prediction of tissue temperature distrbution in bioheat transfer studies. On the other hand, some researchers have discovered that the behavior of waves has to be taken into account in bioheat transfer studies when using fast heating systems. ${ }^{[31,32]}$ This has led to the proposal of the thermal wave theory and thermal wave equation. The thermal wave equation can be expressed as:

$\partial^{2} T / \partial x^{2}-(\rho C \tau / K) *\left(\partial^{2} T / \partial t^{2}\right)-\left[\left(\rho C+\tau W_{b} C_{b}\right) / K\right]^{*}(\partial T / \partial t)+$

$$
\begin{aligned}
& W_{b} C_{b}(T b-T) / K+Q / K=0, \\
& Q=Q_{m}+Q_{r}+\tau\left(\partial Q_{m} / \partial t+\partial Q_{r} / \partial t\right) .
\end{aligned}
$$

Here, $K$ is presumed as a constant; $Q$ represents the changes of tissues in terms of the heat source (including the metabolic rate of tissue); $Q_{m}$ is the thermal energy transformed from chemical energy caused by partial metabolism; $\left[W_{b} C_{b}(T b-T)\right]$ is the blood flow (the thermal energy transmitted from in/out controlled volume blood); $Q_{r}$ shows the volumetric heating; $K$ $\left[\mathrm{W} /\left(\mathrm{m}^{2} \cdot \mathrm{k}\right)\right]$ is the thermal conductivity; $W_{b}\left[\mathrm{~kg} /\left(\mathrm{m}^{3} \cdot \mathrm{s}\right)\right]$ is the blood perfusion rate; $C_{b}$ and $C[\mathrm{~J}(\mathrm{~kg} \cdot \mathrm{k})]$ are the 
specific blood and tissue, respectively; $T b$ and $T\left({ }^{\circ} \mathrm{C}\right)$ are temperatures of blood and tissue, respectively; $Q_{m}$ $\left(\mathrm{W} / \mathrm{m}^{3}\right)$ is the metabolic rate of tissue; $Q_{r}\left(\mathrm{~W} / \mathrm{m}^{3}\right)$ is the volumetric heating rate; and $\tau\left(\mathrm{kg} / \mathrm{m}^{3}\right)$ is the density of tissue. ${ }^{[33]}$

Because the thermal wave equation is hyperbolic, it is common to use a numerical analysis instead of an analytic solution. Furthermore, due to the large temperature gradient observed in a thermal energy input spot on the skin surface when the laser is heating the tissue for a short time, we can neglect the temperature diffusion on the skin surface and focus primarily on heat transfer, which occurs in the same direction as the thermal energy input. The equation can be simplified as a one-dimensional equation for applying to the definite difference model to find the solution to the thermal wave equation. ${ }^{[34-36]}$

At a high energy and a high heat flux of laser illumination, the heat convection effect is not apparent, and can be disregarded. The temperature of the surrounding environment was also not a significant factor. However, temperature decreases when the thickness of tissue increases. As human skin tissue contains three layers epidermis (thickness is $0.00008 \mathrm{~m}$ ), dermis (thickness is $0.002 \mathrm{~m}$ ) and hypodermis (thickness is $0.01 \mathrm{~m}$ ) the thickness of human tissue would be $0.01208 \mathrm{~m}$. When including laser illumination on the skin surface, the difference between Boundary Conditions and Initial Conditions should be considered. During laser application, it is necessary to consider burn injury when the skin temperature is $44{ }^{\circ} \mathrm{C} \cdot{ }^{[37]}$ Second or third-degree burns on the skin will result if temperature increases and it is therefore necessary to carefully control skin surface temperature. Because of the close relationship between the temperature of the skin surface and the energy density of laser illumination, it is important to avoid burn injury when using lasers of different energy densities within certain times and areas.

Since the characteristic time of tissue $(\tau)$ has significant influence on temperature prediction, the result derived using the thermal wave equation with the thermal wave effect can be more accurate. For biological tissues, $\tau$ is defined as the characteristic time needed for accumulating the thermal energy required for propagative transfer to the nearest element within nonhomogeneous inner structures. That is, it is the time needed for the temperature of objects to drop by half from the warmest temperature after being illuminated with a laser.

For general homogeneous materials, $\tau$ is defined as the thermal relaxation time. The effect of the thermal relaxation time $(\tau)$ should be taken into account when applying the thermal wave equation. This factor $\tau$ is neglected in the Pennes equation. Usually the thermal relaxation time $\tau$ for general homogeneous materials is very low, i.e. between $10^{-8}-10^{-14} \mathrm{~s}^{\left[{ }^{[3]}\right.}$ Thermal waves showed no clear effect during heat transfer except when there was a marked change in the heat flux rate. $\tau$ in biological systems has been predicted to be $20-30 \mathrm{~s}{ }^{[31,32]}$

In 1995, researchers like Mitra et al.. ${ }^{[37]}$ conducted experiments on processed meat and obtained the following result: $\tau$ is $16 \mathrm{~s}$. Currently most studies of biological tissues use a $\tau$ of 20 s. $^{[34,35]}$ In this study $\tau$ is also set at $20 \mathrm{~s}$. This concept is very important for laser surgeons to choose the correct $\tau$ for the treatment of hyperpigmented lesions such as Nevus of Ota.

Since laser illumination requires using an extremely shortamount of time and its heat flux being tremendously high, the thermal wave effect is very clear during heat transfer, and therefore, our study conducted an analysis with the thermal wave equation to be able to observe and determines skin heat transfer. Currently the most common lasers used in cutaneous surgery for Nevus of Ota are the Q-switched ruby lasers. The wavelength of the QSRL is $694 \mathrm{~nm}$, and the pulse duration is $25 \mathrm{~ns}$. Regarding the input of laser energy, the use of a fixed illumination time on a surface as a boundary condition must also be considered. In order to obtain attainable results, the boundary condition was divided in terms of the energy density of input energy. As to the analytic solution, the separation variable method and superposition principle theory was used to obtain results. This made the discussion of skin heat transfer easier and more precise.

With an ambient skin temperature of $30{ }^{\circ} \mathrm{C}$ and to ensure that the epidermal temperature does not exceed $70{ }^{\circ} \mathrm{C}$ after pulsed laser exposure, the highest permissible "T-jump" $\left(\Delta T_{\text {LASER }}\right)$ is $40^{\circ} \mathrm{C}$. If a preliminary sub-therapeutic diagnostic laser pulse, $D_{0}$, produces a T-jump (because incident energy density is directly proportional to $\left.\Delta T_{\text {LASER }}\right)$ then the threshold for epidermal damage $\left(D_{E}\right)$ is $D_{E}=40 D_{\delta} \Delta T_{\text {LASER }}$.

Consider a simple example to illustrate the principle in a patient with a normal skin surface temperature of $30{ }^{\circ} \mathrm{C}$ : one joule of laser energy delivered to the skin produces a T-jump of $8{ }^{\circ} \mathrm{C}$. Therefore, in order to keep the T-jump after laser illumination at less than $40{ }^{\circ} \mathrm{C}$, such that the epidermal temperature does not exceed $70{ }^{\circ} \mathrm{C}$, the boundary condition should be divided in terms of the energy density of input energy. As to the analytic solution, the separation variable method and superposition principle theory can be used to obtain 
results. This will make the delivery of skin heat transfer easier and more precise.

In our study, real-time monitoring with photothermal images and the prediction of temperature was reliable when using the thermal wave equation. We were able to clearly observe how the temperature distribution of heat transfer and the features of the thermal wave phenomenon were applicable in laser treatment. Our study also showed different predictions of QSRL illumination for different energy density. Results showed that the effective energy density of lasers should be lower than $8 \mathrm{~J} / \mathrm{cm}^{2}$ based on the thermal wave equation if the QSRL is applied to the treatment of skin pathological changes. This result is helpful for doctors in determining the optimum laser energy density while simultaneously minimizing damage to surrounding tissue. Nevertheless, when addressing Nevus of Ota patients with definitive treatment, exact thermal equations, proper procedural analysis of each patient and careful consideration of age, skin type, and area in-line for treatment all must be administered for a successful clinical application.

In conclusion, laser illumination requires an extremely short time and its heat flux is extremely high in cutaneous laser surgery. For prevention of complications, it is necessary to take the thermal wave effect into account. Real-time photothermal imaging and prediction of temperature response on the lesion site derived from this study is helpful for determining the energy density for laser treatment of Nevus of Ota patients. The effective energy density of lasers should be lower than $8 \mathrm{~J} / \mathrm{cm}^{2}$ to avoid complications. This study can serve as a precedent for increased and improved safety of laser surgery patients and lay groundwork for research of other laser treatments.

\section{Financial support and sponsorship}

This projectwas supported by research grants awarded from the National Science Council in Taiwan (NMRPG34661:942213-E-182A-002, NMRPG34662: 95-2221-E-182A-003, NMRPG376311:97-2221-E-182A-001-MY3) and Chang Gung Memorial Hospital (CMRP606, CMRP 812, CMRPG3B0301, CMRPG3B0302, CMRPG3E0581).

\section{Conflicts of interest}

There are no conflicts of interest.

\section{Patient consent}

All patients gave informed consent.

\section{Ethics approval}

The study was approved by the Institutional Review
Board at Chang Gung Memorial Hospital.

\section{REFERENCES}

1. Hidano A, Kajima H, Ikeda S, Mizutani H, Miyasato H, Niimura M. Natural history of nevus of Ota. Arch Dermatol 1967;95:187-95.

2. Font RL, Reynolds AM Jr., Zimmerman LE. Diffuse malignant melanoma of the iris in the nevus of Ota. Arch Ophthalmol 1967;77:513-8.

3. Sang DN, Albert DM, Sober AJ, McMeekin TO. Nevus of Ota with contalateral cerebral melanoma. Arch Ophthalmol 1977;95:1820-4.

4. Taylor CR, Gange RW, Dover JS, Flotte TJ, Gonzalez E, Michaud N, Anderson RR. Treatment of tattoos by Q-switched ruby laser. A doseresponse study. Arch Dermatol 1990;126:893-9.

5. Scheibner A, Kenny G, White W, Wheeland RG. A superior method of tattoo removal using the Q-switched ruby laser. J Dermatol Surg Oncol 1990;16:1091-8.

6. Mohan RP, Verma S, Singh AK, Singh U. Nevi of Ota: the unusual birthmarks: a case review. BMJ Case Rep 2013;2013:bcr2013008648.

7. Wang J, Guo ZZ, Zhang SG, Wang YJ, Wang YB, Xing DG Microsurgical treatment of meningeal malignant melanoma accompanied by nevus of Ota: two case reports and a literature review. Melanoma Res 2013;23:502-4.

8. Tregnago AC, Furlan MV, Bezerra SM, Porto GC, Mendes GG, Henklain JV, Pinto CA, Kowalski LP, de Carvalho GB, Costa FD. Orbital melanocytoma completely resected with conservative surgery in association with ipsilateral nevus of Ota: report of a case and review of the literature. Head Neck 2015;37:E49-55.

9. Rastogi S, Chaudhari P. Pigment reduction in nevus of Ota following leech therapy. J Ayurveda Integr Med 2014;5:125-8.

10. Geronemus RG. Q-switched ruby laser therapy of neuus of Ota. Arch Dermatol 1992;128:1618-22.

11. Taylor CR, Flotte TJ, Gange RW, Anderson RR. Treatment of nevus of Ota by Q-switched ruby laser. J Am Acad Dermatol 1994;30:743-51.

12. Chang CJ, Nelson JS. Q-switched ruby laser treatment of mucocutaneous melanosis associated with peutz-jeghers syndrome. Ann Plast Surg 1996;36:394-7.

13. Chang CJ, Kou CS. Comparing the effectiveness of Q-switched Ruby laser treatment with that of Q-switched Nd:YAG laser for oculodermal melanosis (Nevus of Ota). Br J Plast Surg 2011;64:339-45.

14. Felton SJ, Al-Niaimi F, Ferguson JE, Madan V. Our perspective of the treatment of naevus of Ota with 1,064-, 755- and 532-nm wavelength lasers. Lasers Med Sci 2014;29:1745-9.

15. Zong W, Lin T. A retrospective study on laser treatment of nevus of Ota in Chinese children--a seven-year follow-up. J Cosmet Laser Ther 2014; $16: 156-60$

16. Wen X, Li Y, Jiang X. A randomized, split-face clinical trial of Q-switched alexandrite laser versus Q-switched Nd:YAG laser in the treatment of bilateral nevus of Ota. J Cosmet Laser Ther 2015;18:12-5.

17. Chesnut C, Diehl J, Lask G. Treatment of nevus of ota with a picosecond 755-nm alexandrite laser. Dermatol Surg 2015;41:508-10.

18. Yates B, Que SK, D'Souza L, Suchecki J, Finch JJ. Laser treatment of periocular skin conditions. Clin Dermatol 2015;33:197-206.

19. Sober AJ. The Year Book of Dermatology. Chicago: Mosby; 1997. p. 383-4.

20. Apfelberg DB, Maser MR, Lash H, Rivers J. The argon laser for cutaneou lesions. JAMA 1981;245:2073-5.

21. Apfelberg DB. Argon and Q-switched yttrium-aluminum-garnet laser treatment of nevus of Ota. Ann Plast Surg 1995;35:150-3.

22. Chang CJ, Nelson JS, Achauer BM. Q-switiched ruby laser of oculodermal melanosis (nevus of Ota). Plast Reconstr Surg 1996;98:784-90

23. Lawrence SB, Michael RT. Laser tissue welding: a comprehensive 
review of current and future. Lasers Surg Med 1995;17:315-49.

24. Sethuraman G, Sharma VK, Sreenivas V. Melanin index in assessing the treatment efficacy of $1064 \mathrm{~nm}$ Q-switched Nd-Yag laser in nevus of Ota. J Cutan Aesthet Surg 2013;6:189-93.

25. Tanino $H$. Über eine in Japan häufig vorkommende Nävusform: Naevus fusco-caeruleus ophthalmo-maxillaris Ota: I. Beobachtung über Lokalisation, Verfärbung, Anordnung und histologische Veränderung. Jap J Dermatol Urol 1939;46:107-11. (in German)

26. Sun YS, Weng CI, Chen TC, Li WC. Estimation of surface absorptivity and surface temperature in laser surface hardening process. Jpn J Appl Phys 1996;35:3658-64.

27. Ting K, Chen KT, Cheng SF, Lin WS, Chang CJ. The prediction of skin temperature distribution in cosmetic laser surgery. Int $J$ Appl Phys 2008;47:361-7.

28. Tejasvi T, Sharma VK, Kaur J. Determination of minimal erythemal dose for narrow band-ultraviolet B radiation in north Indian patients: comparison of visual and Dermaspectrometer reading. Indian $J$ Dermatol Venereol Leprol 2007;73:97-9.

29. Ramsing DW, Agner T. Effect of glove occlusion on human skin. (I). short-term experimental exposure. Contact Dermatitis 1996;34:1-5

30. Magaribuchi T, Ito Y, Kuriyama H. Effects of rapid cooling on the mechanical and electrical activities of smooth muscles of guinea pig stomach and taenia coli. J Gen Physiol 1973;61:323-41.

31. Liu J. Uncertainty analysis for temperature prediction of biological bodies subject to randomly spatial heating. $J$ Biomech 2001;34:163742.

32. Zhang XS, Zhu YS, Thakor NV, Wang ZM, Wang ZZ. Modeling the relationship between concurrent epicardial action potentials and bipolar electrograms. IEEE Trans Biomed Eng 1999;46:365-76.

33. Lu WQ, Liu J, Zeng Y. Simulation of the thermal wave propagation in biological tissues by the dual reciprocity boundary element method. Eng Anal Bound Elem 1998;22:167-74.

34. Torvi DA, Dale JD. A finite element model of skin subjected to a flash fire. J Biomech Eng 1994;116:250-5.

35. Diller KR, Hayes LJ. Analysis of tissue injury by burning: comparison of in situ and skin flap models. Int J Heat Mass Transfer 1991;34:1393406.

36. Kaminski W. Hyperbolic heat conduction equation for materials with a non-homogeneous inner structure. J Heat Transfer 1990;112:555-60.

37. Mitra K, Kumar S, Vedavarz A, Moallemi MK. Experimental evidence of hyperbolic heat conduction in processes meat. $J$ Heat Transfer 1995;117:568-73. 